\title{
Internal Logistics Flow Simulation: a case study in automotive industry
}

\author{
Marcelus Fabri Lima ${ }^{\text {ab }}$, Helena Ramalhinhoc ${ }^{c}$, Miquel Oliver ${ }^{\mathrm{a}}$ and Juan Carlos \\ Muñoz ${ }^{b}$

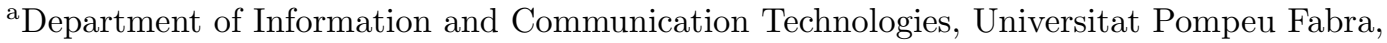 \\ C/ Roc Boronat, 138, 08018, Barcelona, SPAIN. \\ bSEAT, S.A. Autovía A-2, Km. 585, 08760, Martorell, SPAIN. \\ ${ }^{\mathrm{c}}$ Department of Economics and Business, Universitat Pompeu Fabra C/ Trias Fargas, \\ 25-27,08005, Barcelona, SPAIN.
}

\begin{abstract}
This work focuses on internal logistics (IL), which is defined as the flows of materials inside the same business or the same plant. We center on the IL activities of a car-assembling company. The main objective is to propose simulation models' concepts that evaluate assembling lines under the IL point of view. Also, we present a real case-study based on SEAT S.A., a company in the Volkswagen group. We developed a Discrete-Event-Simulation model through the Plant Simulation software. The company set the main Key-Performance-Indicators, and these are related to the logistics flows' performance and an assembly lines' aisles utilization. Three scenarios were simulated: the company's current scenario, the introduction of autonomous automated guided vehicles, and the application of a transit flow policy. The results expose which aisles are overused, the disturbs among the logistics flows, and the logistics flows' performance, regarding the total of backorders, the trips duration, and the routes' length in terms of distances and time. Moreover, we offer a set of best practices for further applications in that field. The study was presented to the company's employees that found it interesting and appropriate.
\end{abstract}

\section{KEYWORDS}

Logistics; Automotive Industry; Discrete-Event Simulation

\section{Introduction}

The logistics field refers to the flow of materials between and within organizations. Also, it is a vital field to gain competitiveness in the market by reducing costs or serving better the customers, see (Muñuzuri, Larrañeta, Onieva, \& Cortés, 2005). Most of the works published in the logistics field focus on external logistics, i.e., flows of materials and products to different companies or customers, see (Tako \& Robinson, 2012) and (Braekers, Ramaekers, \& Van Nieuwenhuyse, 2016). In this work, we focus on internal logistics, which means flows of materials inside the same business or the same plant, for example, from the warehouse to an assembly line. The improvement of these flows can lead to a reduction in the delays, disruptions, accidents, and also contribute to minimizing the logistics costs. As a result, the main objective of this work is to propose simulation-based concepts that evaluate assembling lines under the internal logistics point of view. 
The motivation to study the Internal Logistics Flow (ILF) in an assembly line comes from the study of a real case based on the company SEAT S.A.(Sociedad Española de Automóviles de Turismo) which is a Spanish company, a subsidiary of the Volkswagen Group (www.seat.es). SEAT's market is composed of more than 75 countries, with a volume of sales in 2018 of more than 517,600 units. This study was carried out under an agreement with SEAT S.A., which expressed to us the importance of analyzing assembly lines focus on the internal logistics processes. The company also provided us with all the necessary data and support.

To analyze the ILFs, we consider the simulation methodology described by (Banks, Carson, Nelson, \& Nicol, 2005). Also, according to those authors and (Tako \& Robinson, 2012), simulation is a suitable methodology to face logistics problems. Among the simulation methodology applications, we can find the System Dynamics, Agentbased Modelling, and Discrete-Event Simulation (DES). Also, simulation models have been extensively used to deal with logistics problems, as observed in (Banks et al., 2005; Hillier \& Lieberman, 1995; Tako \& Robinson, 2012). As stated, there are many simulating-based works that focus on external logistics. However, there are a limited number of works applied to the internal logistics (IL) field. Nevertheless, most of those simulation-based studies that associate assembly lines and IL are focused on the production point of view because they consider aspects such as the production flow in the assembly line and machine interruptions.

The main goal of this work is to propose a simulation model to evaluate and analyze the internal logistics activities in an assembly line of a car-manufacturing company. We developed a DES model through the Plant Simulation software and performed an analysis of the IL in SEAT. To evaluate the IL, we have considered Key Performance Indicators (KPI) proposed by the company. These KPIs are related to the logistics flows' performance and the assembly line's aisles utilization. Moreover, three scenarios were evaluated based on the actual system, the introduction of autonomous automated guided vehicles (AGV), and applying a transit flow policy. The results indicated the main aspects and areas of the assembly line that contribute to a disruption of the logistics operations. Note that the proposed DES concepts can be applied whenever a new scenario occurs or even in other industries that rely on assembly lines. As a result, we present a set of best practices for bench-marketing purposes for those who develop DES models centered on ILF analysis, because it is a vital topic for businesses that count with assembling lines.

Moreover, the automotive sector can be viewed as a particular case regarding manufacturing companies. First, a significant amount of data is required to conduct a DES study over an entire assembly line. Usually, that sector does not disclose that required data. Second, the complexity of the DES is significant in terms of the number of processes. There are many processes to be considered because many types of ILFs are introduced into the model. Third, besides the ILF processes, there are the workstations' orders to take into account. In SEAT, one assembling line can produce more than 600 cars each day. Also, a car is assembled with more than 2,500 materials in those workstations. So, the scope of the DES model is quite significant. As a result, businesses that share similar concepts, but on a smaller scale, can take advantage of this work as well.

The paper is organized as follows. Section 2 presents the literature review and the main contribution of this work. Section 3 presents the case-study description. Section 4 describes the developed simulation model and the experiments' results. Finally, section 5 concludes the paper. 


\section{Literature review}

This paper is placed among those simulation-based works that are related with the Logistics and Production fields. In particular, that work addresses to the internal logistics field. So, in this section, we highlight the works that share some concepts with our approach.

Usually, the literature associates the logistics related works to the Supply Chain Management (SCM) studies. That can be checked in the surveys and literature revisions presented by (Sachan \& Datta, 2005; Tako \& Robinson, 2012; Wilding, Wagner, Gligor, \& Holcomb, 2012).

The survey conducted by (Sachan \& Datta, 2005) reviewed 442 papers of SCM and logistics research to examine the state of logistics and SCM research. Surprisingly, only 20 out of these 442 papers used simulation as the primary methodology.

Moreover, (Wilding et al., 2012) conducted a review of the literature on manufacturing, organizational, and SCM agility through 175 papers. The authors concluded that SCM agility had been explored through a focus on manufacturing flexibility, supply chain speed, or lean manufacturing. Another interesting point is the fact that there is not any work in these surveys, in which the main scope focuses on internal logistics. However, internal logistics is a theme to be considered when facing logistics concepts.

Finally, (Tako \& Robinson, 2012) presented a survey on simulation studies under Logistics and SCM perspectives and their application in several industries. Their work suggests that the DES has been applied more frequently to work on SCM. On the other hand, the Systems Dynamics method is the preferred one to deal with the bullwhip effect. On the contrary, no important information was provided regarding ILF studies.

Centralizing the search over manufacturing logistics studies, which is one of the main topics of our work, there are two surveys to highlight. These are the studies presented by (Negahban \& Smith, 2014; Semini, Fauske, \& Strandhagen , 2006).

(Negahban \& Smith, 2014) conducted a review of 290 DES publications with a focus on applications in manufacturing. The authors classified the literature into three classes: (i) manufacturing system design, (ii) manufacturing system operation, and (iii) simulation language/package development. Even though the authors did not create a specific category for logistics, the logistics-based works were somehow considered through the studies of automated material handling systems. Also, the authors pointed out that logistics-based works were mostly related to AGV. So, no further discussion about ILF concepts was provided.

Regarding the AGV-based works, a complete survey about design and control of AGV systems is presented by (Vis, 2006). In this AGV systems survey, the author considers topics related to flow path layout, traffic management, and vehicle routing. So, issues like single loops, tandem, and segmented flow configurations are discussed. However, the focus is always on the AGV itself and not on how an AGV interacts with the environment.

Also, (Semini et al., 2006) presented a survey on the use of DES in real-world manufacturing logistics decision making. The authors conclude that the majority of applications have been classified into the following fields: production plant design, evaluation of production policies, lot sizing, work in progress levels, and production plans/schedules. We can state that this survey supports the argument that the literature lacks works that consider both workshops' aisles utilization and flows strategies. Indeed, (Semini et al., 2006) did not present a work like that.

Therefore, from the best of the authors' knowledge, there is not a similar work that faces the internal logistics flow and the traffic issues inside a workshop, as we propose 
in this paper.

On the contrary, it does exist works that share common aspects of the ILF topic. We introduce these works through four categories: (i)production flow, (ii) layout evaluation, (iii) material handling flow, and (iv) routing strategy. Table 1 summarizes those works.

Works that tackle issues related to Production Flow are: (Ĉujan , 2016; Ruiz-Torres \& Nakatani, 1998; Seebacher, Winkler, \& Oberegger, 2015). Also, works that center their approach to the automotive sector and the production flow are: (Fabri, Ramalhinho, de Souza, \& Ravetti, 2019; Faget, Eriksson, \& Herrmann, 2005; Ludavicius \& Ali, 2014; Michalos, Makris, Papakostas, Mourtzis, \& Chryssolouris, 2010; Patchong, Lemoine, \& Kern, 2003; Roman-Verdugo, 2014).

Regarding works that face issues linked to Layout Evaluation, see (Horta, Coelho, \& Relvas, 2016; Martínez-Barberá \& Herrero-Pérez, 2010; Wang \& Chang, 2015).

Concerning works that focus on Material Handling Flow (MHF), see (Klug, 2013; Mason, Ribera, Farris, \& Kirk, 2003; Zhou \& Peng, 2017). Moreover, there are works that approache both MHF and warehouse issues, such as (Atieh et al., 2016; Caridade, Pereira, Ferreira, \& Silva, 2017; Gagliardi, Renaud, \& Ruiz, 2007; Higgins, Ladbrook, Khalwadekar, \& Osman, 2019; Poon et al., 2009; Ribino, Cossentino, Lodato, \& Lopes, 2018).

Finally, (Lima \& Ramalhinho, 2017; Mehami, Nawi, \& Zhong, 2018; Vavrík et al., 2017) presented studies, in which the Routing Strategy.

\begin{tabular}{lr}
\hline The work's focus & References \\
\hline Production Flow & (Ĉjan , 2016; Fabri et al., 2019; Faget et al., 2005), \\
(Ludavicius \& Ali, 2014; Michalos , 2010) \\
(Patchong et al., 2003; Seebacher et al. , 2015), \\
Layout Evaluation & (Roman-Verdugo, 2014; Ruiz-Torres \& Nakatani, 1998), \\
\hline Material Handling & (Horta et al., 2016; Wang \& Chang, 2015), \\
Flow & (Atieh et al. , 2016; Caridade et al. , 2017), \\
& (Gagliardi at al., 2007; Higgins et al., 2019; Klug , 2013), \\
(Mason et al. , 2003; Poon et al. , 2009), & (Ribino et al., 2018; Zhou \& Peng, 2017) \\
\hline Routing Strategy & (Lima \& Ramalhinho, 2017; Mehami et al. , 2018), \\
(Vavrík et al. , 2017)
\end{tabular}

Table 1. Related work.

To sum up, although there are many references that approach both logistics and manufacturing activities through DES or other simulation-based methodologies, works that focus on the simulation of Internal Logistics Flows (ILF), under an aggregate perspective, are unusual. To the best of the authors' knowledge, the simulation literature lacks studies that integrate more than one class of ILF to evaluate how a workshop can absorb all the traffic, for instance. Also, from our point of view, the absence of simulation studies in the literature over ILF in the automotive sector may be explained by its complexity and confidential issues, as detailed at the end of Section 1.

As a result, the majority of the simulation-based works found in the literature that copes with logistics and production fields concerns with supply chain and productoriented manufacturing optimization. Also, assembly-lines studies have always been 
driven by the workstations necessities, but little attention was put into the logistics flow implications inside an assembly line.

Consequently, this paper provides DES's concepts whose objective is to assess the ILF in an assembling workshop. Besides, we provide a set of bench-marketing practices for those who want to approach the DES to evaluate models centered on ILF analysis, as presented in Figure 3. We are sure that it is a hot topic for a business that counts with assembling lines.

In this sense, our work contributes to knowledge since it copes with a demanded problem over a real scenario. We also present a set of best practices that help to deal with these types of problems and their applications.

\section{The Internal Logistics Flow Simulation in assembling lines}

The Internal Logistics Flow (ILF) analysis is a relevant issue for companies, in particular for those that face a scenario with high variable demand. A proper ILF simulation study enables a company to carry on analysis of the followings items: (i) flow bottlenecks; (ii) layout evaluation; and (iii) introduction of new premises such as the input of traffic new rules or a new product. As a result, this approach summarizes the standard aspects of ILF simulation in assembling lines. Also, it is highly recommended whenever there are relevant changes in the system, such as the operations of an assembly line or introduction of a new logistics flow.

In this work, we execute an ILF simulation based on a DES model to evaluate the workshop's aisles and the introduced logistics flows. The main goal is to identify the main bottlenecks in the system, which regards to the ILFs obstructions found throughout the simulation, such as blocked trajectories and overtakes. Consequently, we will be able to verify which aisles are more collapsed in terms of traffic. Therefore, we aim to present a case study of a DES model, which focuses on the logistics flows aspects. Next, we present the special characteristics found in ILF processes of SEAT.

We highlight that the departure frequency of a route depends on the material consumption rate assigned to it. Consequently, materials with non-uniform consuming rates are delivered not periodically as well. Then, the convoys, which have these material assigned, will depart under demand. On the contrary, some materials are regularly requested. These materials are assigned to another class of convoys. As a result, we state that there are two main classes of convoys, those with irregular departure and those with regular departures.

Next, the main processes observed in the supplying activity in SEAT are presented. First, we explain figure 1 that regards to irregular logistic flows. In other words, those logistics flows whose departure from the warehouse towards the assembly line are not periodical. Later, those flows with periodic departure are presented in figure 2. Note that those processes presented by figures 1 and 2 were considered to develop the DES model.

Figure 1 presents four steps to take into account: (i) departure from the warehouse (WHS), (ii) check workstations, (iii) supply workstations and (iv) return back to the WHS. Each step is explained next.

First, the WHS receives orders through the commercial system SAP. Note that these orders are not steady in this case, which results in irregular departures. As a result, the departure is regulated through a rule defined as a "Capacity vs. Time" rule. This rule ensures that each convoy leaves the WHS as soon as it is either completely loaded or after a pre-defined amount of time. The last criterion refers to the amount of time 


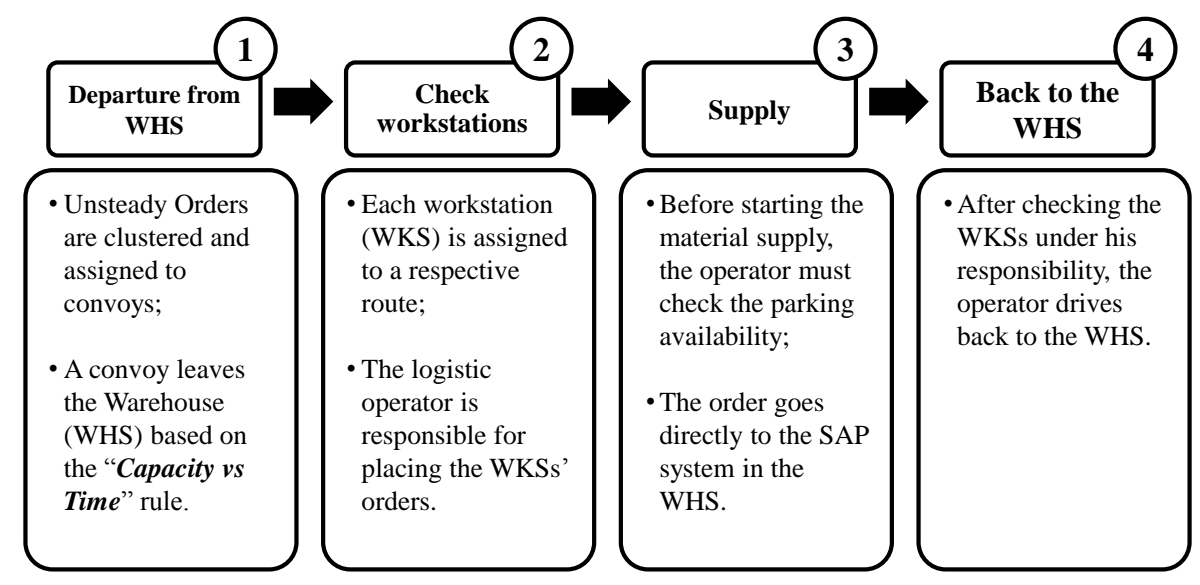

Figure 1. The summary of the processes of a logistic flow, which does not present a periodic departure.

a convoy can wait after the arrival of the first order. For example, the maximum time a convoy can wait to be loaded is 30 minutes after assigning the first material to it. Then, there are two criteria that regulate the departure, which refer to the capacity and the time. Also, there is an important material' classification that concerns to the Stocking Keeping Unit's (SKU) size. In the company, there are two main classes of SKU, i.e., the Small Boxes (SB) class and the Large Container (LC) one. So, we state a premise that establishes the division between SB convoys and LC ones. In other words, it is not allowed to mix SB and LC in the same convoy. That premise is coherent with SEATs actual processes.

Afterward, the second phase starts, which refers to the checking workstations processes. In SEAT, one operator is assigned to one route. Also, several workstations are linked to each route. Moreover, one workstation cannot be served by more than one route. That rule is valid for SKU-related routes only. Other relevant premises refer to the logistics flows' trajectory. By definition, a logistics flow must complete all its trajectory whenever it starts. Also, the considered logistics flow trajectories must be conserved and kept fixed for a long-term period, e.g., months. It is justified because some logistics operators are responsible for supplying the orders and placing orders. As a result, the routes are fixed to keep the requesting and supplying activities under control. In the next section, we will identify the characteristics of the studied logistics flows.

Later, the third phase refers to the supplying activity. Along a route trajectory, an operator must park the convoy to supply a workstation, and each workstation has its parking spot. So, if there is not any spot available, the operator must wait for an empty spot. Then, the operator will supply the material and restart its trajectory.

Lastly, the final step is the return to the WHS. After checking the workstations' under his/her responsibility, the operator returns to the WHS to deliver the empty racks and get newly loaded ones. Later, the convoy departs from the WHS towards the assembly line, and the cycle starts again.

Next, figure 2 presents the processes for those logistics flows that have a regular departure from the WHS (for example, every 15 minutes). These processes are quite similar to the irregular departure ones. On the one hand, the routes are divided into SKU classes, and the routes do not share supplying locations. On the other hand, the materials supplied here are viewed as steady ones because its consumption rate is 
well defined. Therefore, there is no need to ask the logistics operators to place orders because it is ruled by SAP, following the first-in-first-out (FIFO) rule.

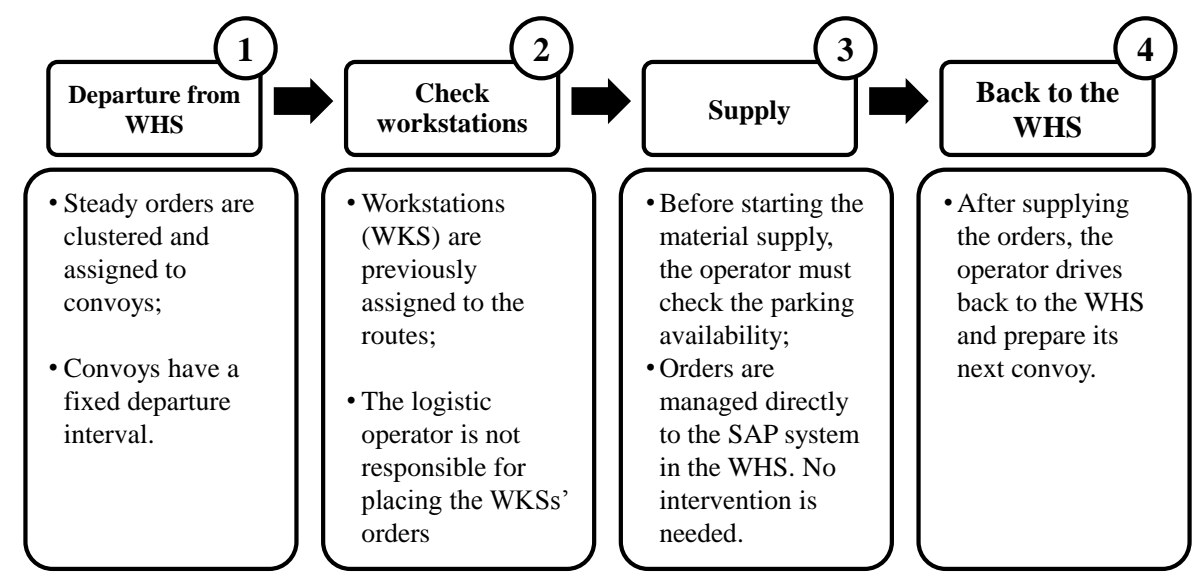

Figure 2. The summary of the processes of a logistic flow, which presents a periodic departure.

Then, we evaluated these flow classes through an assembling-line simulation model. That model was developed based on classical simulation models methodologies stated by (Banks et al., 2005; Brooks \& Robinson, 2001), which can be summarized in five steps: (i) problem formulation; (ii) model construction; (iii) data collection; (iv) experiments; and (v) validation. Figure 3 summarizes the main procedures to take into account.

\begin{tabular}{|c|c|c|c|c|}
\hline $\begin{array}{c}\text { Problem } \\
\text { Formulation }\end{array}$ & $\begin{array}{c}\text { Model } \\
\text { Construction }\end{array}$ & $\begin{array}{c}\text { Data } \\
\text { Collection }\end{array}$ & Experiments & Validation \\
\hline $\begin{array}{l}\text { - Set the main } \\
\text { processes; } \\
\text { - Set the main } \\
\text { goals; } \\
\text { - Propose new } \\
\text { premises: Security } \\
\text { issues, Layout, } \\
\text { introduction of } \\
\text { new technologies. }\end{array}$ & $\begin{array}{l}\text { - Set the scope; } \\
\text { - Define: Logistics } \\
\text { routes, crossing } \\
\text { rules, speed, } \\
\text { overtakes rules, } \\
\text { supplying time, } \\
\text { routes departures } \\
\text { and requests } \\
\text { procedure; } \\
\text { - Terminal or } \\
\text { continuous sim. }\end{array}$ & $\begin{array}{l}\text { - Input data set by } \\
\text { the company; } \\
\text { - Special attention } \\
\text { with routes- } \\
\text { departure } \\
\text { frequency and } \\
\text { convoys' } \\
\text { supplying time; } \\
\text { - Define } \\
\text { determinitic and } \\
\text { stochastic data. }\end{array}$ & $\begin{array}{l}\text { - Reproduce the } \\
\text { current scenario; } \\
\text { - Introduce new } \\
\text { premises one-by- } \\
\text { one; } \\
\text { - Set the KPIs. First } \\
\text { focus on defined } \\
\text { KPIs by the } \\
\text { company. Then } \\
\text { propose others if } \\
\text { necessary. }\end{array}$ & $\begin{array}{l}\text { - Get feedback from } \\
\text { the experts and } \\
\text { decision-makers } \\
\text { from all } \\
\text { hierarchical levels; } \\
\text { - Validate the } \\
\text { simulation } \\
\text { bottlenecks; } \\
\text { - Evaluate the KPIs. }\end{array}$ \\
\hline
\end{tabular}

Figure 3. The classical simulation modeling framework and the best practices over an assembling-line model construction.

As presented in Section 2, most of the literature prioritizes the manufacturing issues and considers the body-shop phase when car-assembling lines are evaluated. In this work, we provide a set of best practices for those who develop DES models centered on ILF analysis. Next, we present the simulation model that copes with the ILF processes.

\section{The Simulation Model Description}

In this section, we present the DES model applied to the ILF of two car-assembly lines, which is motivated by the application at SEAT. 
The DES model developed here is defined as a terminating simulation model, as stated by (Banks et al., 2005). Besides, it follows the concept of the building blocks design. According to (Valentin, Verbraeck, \& Sol, 2003), building blocks are suitable for logistics environments because there are processes that repeat over the model. As a result, we developed routines so users can drag and drop them in the frame. Furthermore, some parameters of the model are done through excel tables that can be filled by the user previously. Then, to explain better the model's concepts, we present the simulation model through the framework illustrated in Figure 3.

\subsection{Problem Description}

The first step concerns the problem description. It consists of three main phases: (i) set the main processes; (ii) set the main goals; and (iii) propose new premises, such as a new layout and the introduction of new technologies. The main processes have already been presented in the last section by figures 1 and 2. Next, the main goal of this work is identifying the logistics flows' bottlenecks through a simulation model that considers a company's workshop. Also, evaluating the consequences of introducing a set of established premises, such as layout, convoys' speed, and workstations demands. Finally, the new premises evaluated are the introduction of an autonomous AGV and a single flow traffic policy. Note that our model does not consider the content of the supplied boxes and containers but the number of SKU units to be supplied.

\subsection{Model Construction}

The second framework's step is model construction. We modeled the problem through a DES Model. To provide a better understanding of the model and set its scope, we present the main concepts of the model as follows: (i) layout; (ii) traffic flow; (iii) irregular routes departure; (iv) supplying activity; and (v) KPIs report.

The first concept is the layout one that is defined by the aisles and intersections rules. Here, the main traffic rules are stated, such as overtaking permissions, intersection priorities, and workstations' locations. Figure 4 illustrates the layout developed through the Plant Simulation software. The dimensions of the studied workshop are nearly 350 meters in width by 60 meters in length. Moreover, it contains two assembly lines that process more than 1,000 cars per day. The workshop is divided into two main parts, with different logistics operations. The left-hand part contains verticals aisles as the majority, and it is called Supermarket. Next, the right-hand part has horizontal aisles as a majority and is viewed as the assembly line area. We highlight that both of these areas are considered in this work because both of them must receive materials through the logistics flows. However, the supermarket is also a location where logistics flows depart as well.

Second, to set the traffic rules in all the workshop' areas, we develop traffic flow concepts that are responsible for defining items such as routes' directions, departures, and a convoy's decision whether an overtaking is possible or not.

The third concept regards to the irregular convoys departures that refers to those routes called as supplying ones. It concerns the logistics flows that are in charge of supplying the materials with a variable consumption rate. The workstations' consumption or orders are available in the company's SAP system. We introduce in the model those orders that refer to real-historical data. Therefore, these workstations' demands are the main variable components of the DES model. Figure 5 illustrates how orders 


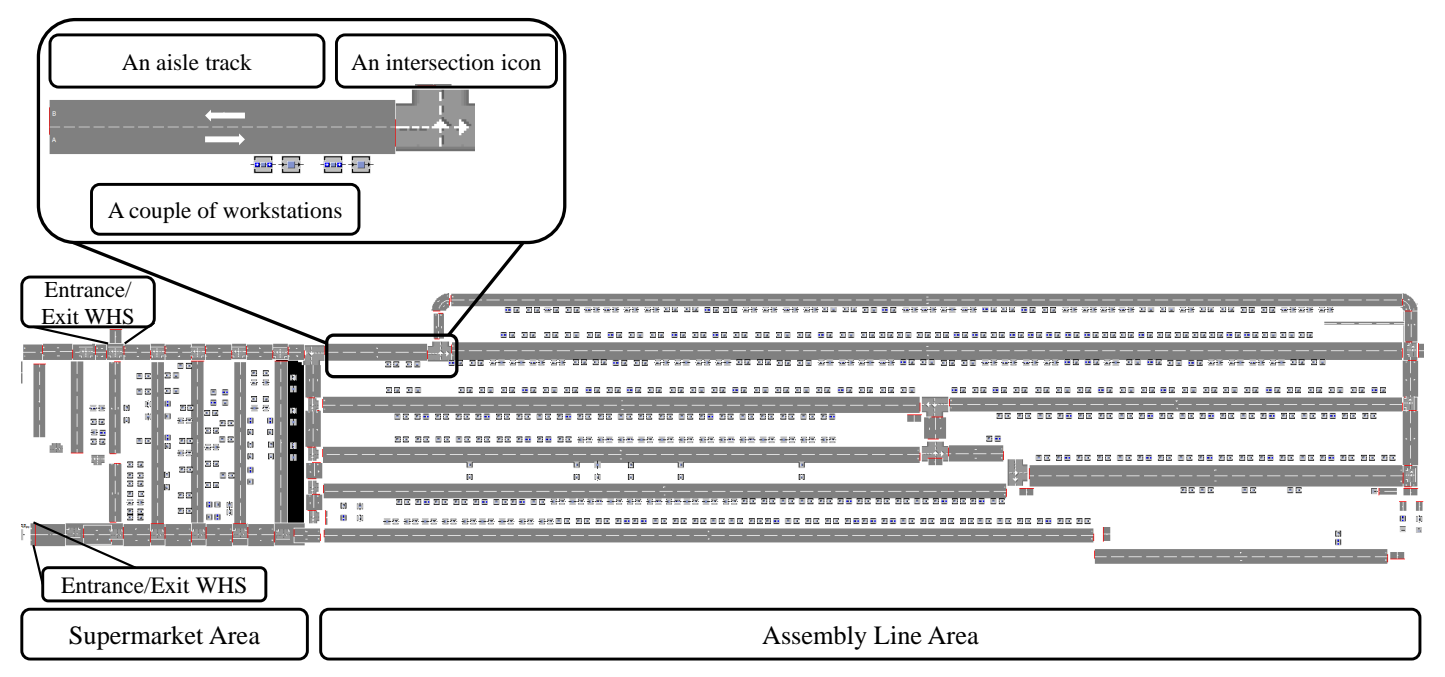

Figure 4. The layout of the studied workshop. It is compound by a set of aisles (tracks) and a set of workstations (grey dots). Besides, there are two main parts. The left-hand part, which contains long verticals aisles, is called Supermarket. Next, the right-hand part, which contains long horizontal aisles, is viewed as the assembly line zone.

are placed, along five days, considering one workstation.

Next, we built an algorithm that is in charge of assigning requests to the corresponding convoys. By definition, a workstation's orders must be assigned by a unique and pre-established convoy. A convoy's departure is allowed either whenever a predefined time-limited is reached or the number of orders assigned is equal to the convoy's capacity, which refers to the "Capacity vs. Time" rule defined in section 3 . Note that each convoy is unique and refers to a specific route.

The fourth concept is supplying activity. It is relevant because it provides information about how the unloading activity may interfere with both aisle's traffic and over the workstations areas. Particularly, for those workstations that receive both LC and SB materials from more than one convoy.

Finally, the last concept concerns the KPI reporting. To report the KPIs, we collect the data generated by the simulation model. That data gives information about the convoys, aisles, orders as well as interferences data, such as overtaking and logistics flows' interruptions.

To conclude, we state that the developed DES model shares some concepts with the Agent-Based modeling based on the premises stated by (Macal \& North, 2010). On the one hand, we state that each vehicle, or agent, is a modular and uniquely identifiable individual. Besides, we assigned attributes to each vehicle, such as name, route's tracks, workstations to be visited, and departure time. Moreover, those vehicles interact with other vehicles dynamically, as we can observe in the interference data collection. As a result, the vehicles have a sort of protocol for interactions with other vehicles. On the other hand, the vehicles cannot learn and adapt their behavior completely, for example, deciding to change the routes' trajectory due to traffic congestion. In this sense, we assume that our model incorporates some concepts of the agent-based simulation. However, it is a DES model because we modeled a system in which the considered variables change only at a discrete set of points in time. 


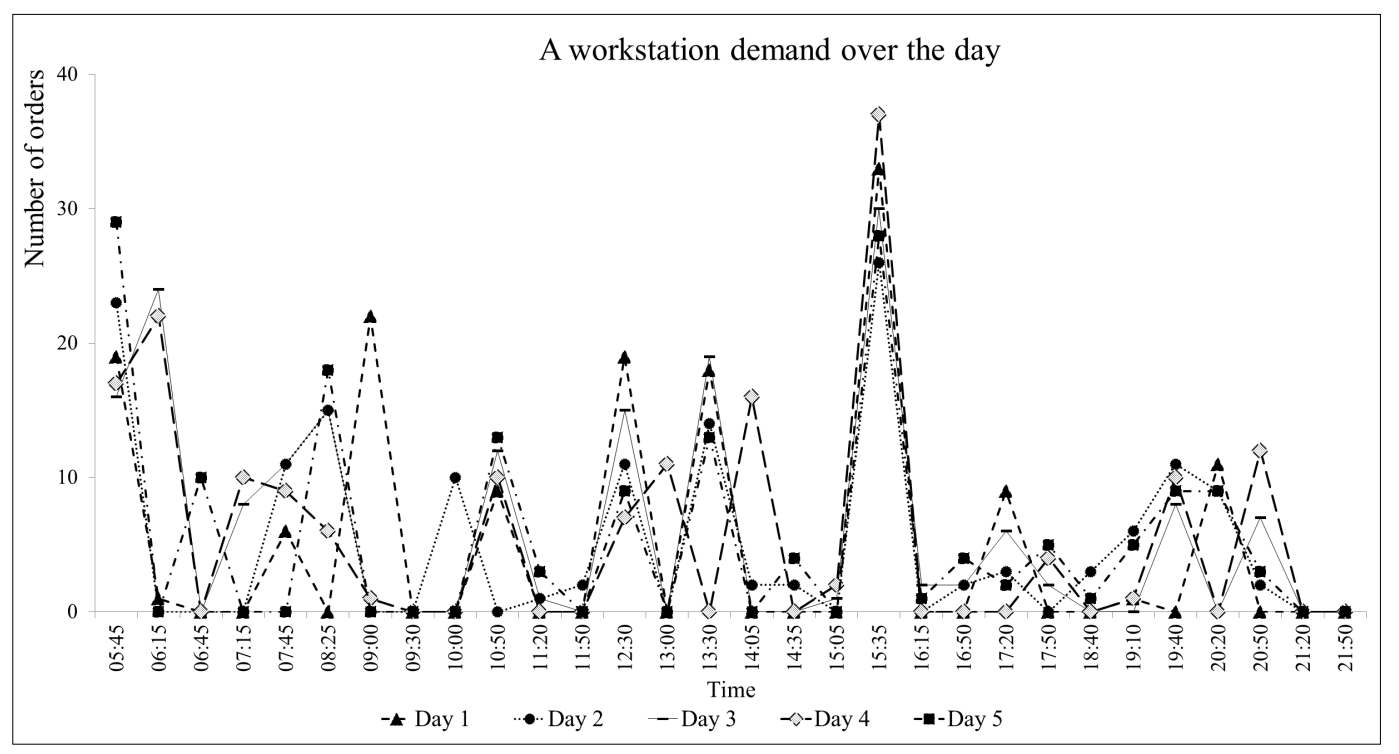

Figure 5. The demand behavior of a workstation throughout five consecutive days.

\subsection{Data Collection}

The third step of the framework is data collection, which was briefly cited in the last step (Model Construction). To carry on this study, we input real data provided by SEAT. Deterministic parameters were defined by the company, such as speed, capacity, and time spent to deliver the material at the correct place. Concerning to the models' input data, we present the table 2 that contains the main parameters applied in this work.

\begin{tabular}{lr}
\hline Data & Value \\
\hline Supplying Average Time LC & $2.69 \mathrm{~min}$ \\
Supplying Average Time SB & $0.66 \mathrm{~min}$ \\
Convoy's Average Capacity LC & $4 \mathrm{units}$ \\
Convoy's Average Capacity SB & $48 \mathrm{units}$ \\
Convoy's Average Speed & $7 \mathrm{~km} / \mathrm{h}$ \\
AGV Convoy's Average Speed & $4 \mathrm{~km} / \mathrm{h}$ \\
Number of workstations & $154 \mathrm{units}$ \\
Number of assembly Lines & 2 lines \\
A Replication Period & One day $(2$ shifts $)$ \\
Warm-up Period & 15 minutes \\
Time-slot for Supplying routes & 30 minutes \\
Number of days applied & Five days
\end{tabular}

Table 2. Summary of the parameters' structure. We highlight that LC means large containers and SB means small boxes.

The orders of 154 workstations are delivered through four main logistics flows, which are presented in Table 3 and defined as follows: (i) supplying route; (ii) cycling route autonomous AGV; (iii) cycling route operator; and (iv) Just-in-Time route (JIT). 
Supplying routes

Cycling routes AGV

Cycling routes Operator

JIT route
Irregular departure; Overtaking allowed; 17 Routes

Regular departure; Overtaking not allowed; 4 Routes

Regular departure; Overtaking allowed; 2 Routes

Regular departure; Overtaking allowed; 5 Routes

Table 3. Summary of logistics flows applied.

To summarize Table 3, the supplying routes refer to the convoys that deliver materials whose consumption rate is irregular, e.g., the workstation described in Figure 5. On the contrary, the following logistics flows receive materials with a constant consumption rate. Therefore, all of them follow a systematic departure routine that we defined as regular departures. Among those flows, there are the "cycle routes AGV" and "cycle routes Operator" that are conducted by an AGV and a logistics operator, respectively. Finally, there are the JIT flows that are executed by outsourced employees. We can not disclose any further data due to confidential issues.

As stated in subsection 4.2, the demand assigned to the supplying routes category is the main variable component introduced in the model. Table 4 present a summary of that data, according to the supplying routes only.

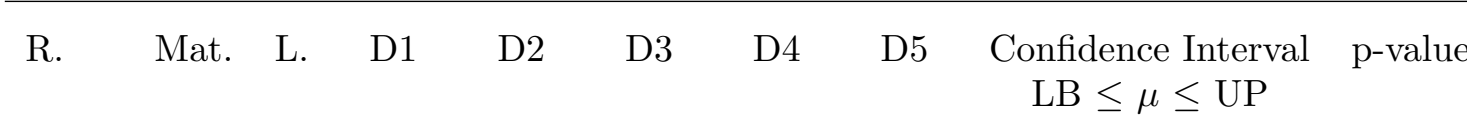

\begin{tabular}{lccccccccr}
\hline 1 & LC & 1 & 243 & 247 & 277 & 287 & 279 & $241 \leq \mu \leq 291$ & 25 \\
2 & LC & 1 & 112 & 115 & 129 & 138 & 135 & $110 \leq \mu \leq 140$ & 15 \\
3 & LC & 1 & 211 & 210 & 239 & 236 & 230 & $208 \leq \mu \leq 242$ & 17 \\
4 & LC & 1 & 163 & 158 & 191 & 180 & 199 & $156 \leq \mu \leq 200$ & 22 \\
5 & LC & 1 & 243 & 231 & 277 & 275 & 285 & $233 \leq \mu \leq 291$ & 29 \\
6 & SB & 1 & 8 & 9 & 14 & 11 & 9 & $7 \leq \mu \leq 13$ & 3 \\
7 & SB & 1 & 67 & 60 & 72 & 68 & 63 & $60 \leq \mu \leq 72$ & 6 \\
8 & LC & 1 & 36 & 37 & 51 & 55 & 44 & $33 \leq \mu \leq 55$ & 11 \\
9 & SB & 2 & 57 & 55 & 67 & 73 & 77 & $54 \leq \mu \leq 78$ & 12 \\
10 & SB & 2 & 306 & 328 & 352 & 328 & 343 & $309 \leq \mu \leq 353$ & 22 \\
11 & LC & 2 & 89 & 79 & 93 & 106 & 103 & $81 \leq \mu \leq 107$ & 13 \\
12 & LC & 2 & 241 & 279 & 286 & 320 & 301 & $249 \leq \mu \leq 321$ & 36 \\
13 & LC & 2 & 225 & 209 & 259 & 277 & 285 & $210 \leq \mu \leq 292$ & 41 \\
14 & LC & 2 & 164 & 177 & 189 & 200 & 190 & $167 \leq \mu \leq 201$ & 17 \\
15 & SB & 2 & 189 & 200 & 221 & 234 & 220 & $190 \leq \mu \leq 234$ & 22 \\
16 & SB & 2 & 244 & 250 & 289 & 280 & 263 & $241 \leq \mu \leq 289$ & 24 \\
17 & LC & 2 & 56 & 62 & 62 & 71 & 69 & $56 \leq \mu \leq 72$ & 8 \\
Total & - & - & 2,654 & 2,706 & 3,068 & 3,139 & 3,095 & $2,644 \leq \mu \leq 3,222$ & 289 \\
\hline
\end{tabular}

Table 4. The summary of the applied variable demand. The first, second, and third columns refer to a routeidentification item, a route's load type and the assembling line assigned, respectively. The five-days demand is presented throughout columns four to eight. The ninth column represents the confidence interval, concerning the route's five-days demand. The LB and UP refer to the lower bound and upper bound values of the CI, respectively. The last column presents the p-value applied to the confidence interval, which is defined as $5 \%$. The last line sums up each component of the table. 
The reader may observe that we introduce a confidence interval (CI) study among the five-days demand sample. It represents the measure of error because the $\mu$ is defined as the average value computed through a sample. As a result, it is an estimated value of the population average $\mu^{*}$. Consequently, $\mu$ has an error that is measured through the CI.

\subsection{Experiments and validation}

The main objective of this work is to analyze the logistics flows' bottlenecks through a simulation model. The developed simulation model evaluates the consequences of introducing all parameters and demands presented previously. So, we consider three scenarios that are presented in Table 5. The objective is to assess those new scenarios and contrast them with the actual system.

\begin{tabular}{lr} 
Scenario & Main Purpose \\
\hline $\begin{array}{l}\text { A - Company's scenario. } \\
\text { B - Introduction of autonomous AGVs. } \\
\text { C - Introduction of a single flow policy. }\end{array}$ & $\begin{array}{r}\text { Enable an AGV to overtake by itself. } \\
\text { One flow aisles whenever possible. }\end{array}$
\end{tabular}

Table 5. Evaluated scenarios.

Based on Table 5, the first scenario aims to compute the current system's metrics. The second scenario evaluates the introduction of an autonomous-AGV concept that enables an AGV to overtake other vehicles by itself and without external support. The purpose is to evaluate how these new robots will affect the level of interferences in the workshop. Lastly, the third scenario refers to the introduction of a single flow policy. So, the workshop's aisles will have a single flow whenever it is possible. Then, for each scenario, we executed five experiments, one for each considered day, see Table 4. Moreover, scenarios $\mathrm{B}$ and $\mathrm{C}$ were defined based on the company's suggestions and discussions. The model was built on the Plant Simulation software (version 13) developed by Siemens.

As explained, that model integrates the workshop layout, the logistics flows, the workstations' demand, and the premises defined by the company. For each scenario, we ran the model five times that correspond to the orders of each day considered.Besides, we set the simulation time as one day, and we considered two shifts within a day. As mentioned, the introduced demand presents different values along the days and different levels over a single day, see Figure 5 and Table 4 . However, all other parameters, such as speed and convoys' capacity, were maintained.

Afterward, we evaluated the experiments' results under the company's KPIs. These KPIs concerns to the routes and aisles utilization. Considering the performance of the routes, we evaluate each route individually based on the following indicators: (i) total of backorders; (ii) backorders' duration; (iii) trip's duration; and (iv) a route's trip distance. Notice that we define a backorder as a material that was supplied later than its due date.

Then, regarding the aisles' performance, we take into account the following indicators: (i) total of interferences; (ii) interferences' duration; and (iii) total of vehicles that passed through each aisle along the day. As mentioned in Section 3, interferences are actions that disturb a convoys' trajectory. In this sense, an interference may be an 
overtaking along an aisle or breaking at the intersections, for instance. Furthermore, we classify the interferences into five groups defined as follows: (i) overtake; (ii) blocked AGV; (iii) waiting before the intersection; (iv) overtake with both vehicle moving; and (v) overtaking not allowed.

Next, we present the computed KPIs in Tables 6, 7, and 8. Also, these tables present the results of the scenarios A, B, and C. Note that the KPIs are computed after 15 minutes of warm-up.

Table 6 presents the results related to aisles' performance. Each table's line represents a different workshop's aisle. So, for each aisle and each scenario, we indicate the total of interferences, the length of those interferences last, and the total of vehicles that passed through that aisle along the day.

As said, we execute five experiments per scenario that correspond to the data provided and allowed to be disclosed in this work. Moreover, each experiment was replicated just once because the variability is linked to a day's orders only. Also, to present the aisles' results accurately, we selected the main ones to expose the results. The criteria to select an aisle was based on its average number of interferences throughout the simulation.

\begin{tabular}{|c|c|c|c|c|c|c|c|c|c|}
\hline \multirow[t]{2}{*}{ Aisle } & \multicolumn{3}{|c|}{$\begin{array}{c}\text { Total } \\
\text { Interf. (units) } \\
\text { Scenarios }\end{array}$} & \multicolumn{3}{|c|}{$\begin{array}{l}\text { Duration } \\
\text { Interf. (min) } \\
\text { Scenarios }\end{array}$} & \multicolumn{3}{|c|}{$\begin{array}{c}\text { Total } \\
\text { vehicles (units) } \\
\text { Scenarios }\end{array}$} \\
\hline & $\mathrm{A}$ & B & $\mathrm{C}$ & A & B & $\mathrm{C}$ & A & B & $\mathrm{C}$ \\
\hline 1 & 142 & 139 & 151 & 14 & 5 & 23 & 613 & 618 & 636 \\
\hline 2 & 126 & 132 & 91 & 7 & 0 & & 439 & 44 & 379 \\
\hline 3 & 92 & 93 & 103 & 4 & 4 & 9 & 414 & 421 & 330 \\
\hline 4 & 68 & 68 & 58 & 3 & 3 & 3 & 529 & 525 & 503 \\
\hline 5 & 44 & 45 & 51 & 2 & 2 & 2 & 515 & 520 & 335 \\
\hline 6 & 40 & 47 & 90 & 2 & 2 & 3 & 332 & 338 & 532 \\
\hline 7 & 17 & 18 & 15 & 3 & 3 & 2 & 588 & 592 & 569 \\
\hline 8 & 7 & 8 & 6 & 1 & 1 & 1 & 1031 & 1050 & 943 \\
\hline 9 & 6 & 6 & 6 & 1 & 1 & 1 & 647 & 659 & 594 \\
\hline 10 & 6 & 7 & 4 & 1 & 1 & 1 & 659 & 672 & 656 \\
\hline 11 & 6 & 6 & 6 & 1 & 1 & 1 & 558 & 566 & 627 \\
\hline Total & 555 & 569 & 581 & 4 & 3 & 5 & 6325 & 6406 & 6104 \\
\hline
\end{tabular}

Table 6. The summary of the aisles' result throughout the three considered scenarios. It is sorted in a decreasing fashion, according to the number of interferences. Only aisles with a relevant number of interferences were selected. Note that the values of each column refer to the average results computed through the simulation of the five-days data. The last line sums up each component of the table, in which we present the sum of the total interferences and vehicles. Also, the average value of the duration of the interferences is presented.

In addition to Table 6 , we provide the Figures 6 and 7 that illustrate the heatmaps layouts of the workshop, which were built based on the number of interferences. Moreover, we assume the following references to set these heat maps: blue color, or the absence of geometric symbols, is set if the number of interferences is fewer o equal to 4; yellow, or squares icons, for a total of interferences values between 5 and 15; red, or circles, applied for a total of interferences values bigger than 15 .

The reader may notice that the conflicting areas are placed where there is a higher concentration of workstations. Usually, these areas receive all kinds of logistics flows. 


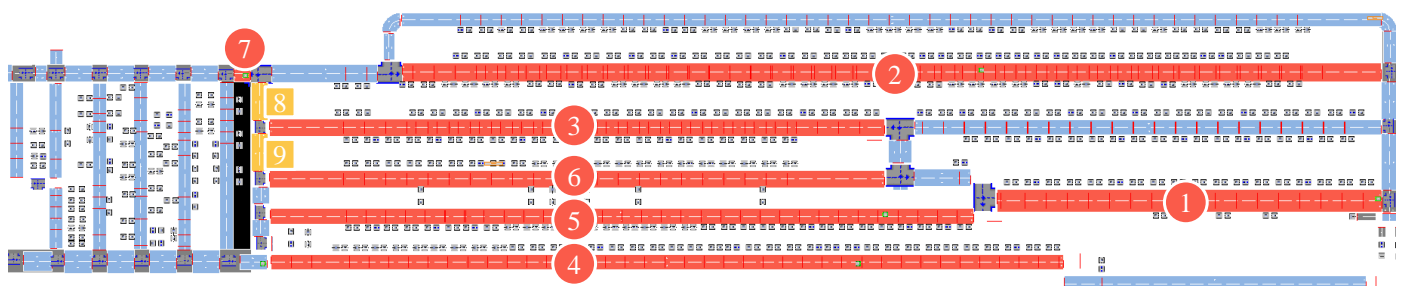

Figure 6. A heat map based on the workshop's layout and the number of interferences computed through the simulation of the scenarios A and B. Notice that the level of interferences is quite similar in both scenarios. However, those scenarios' interferences are not the same ones, as observed in table 7 .

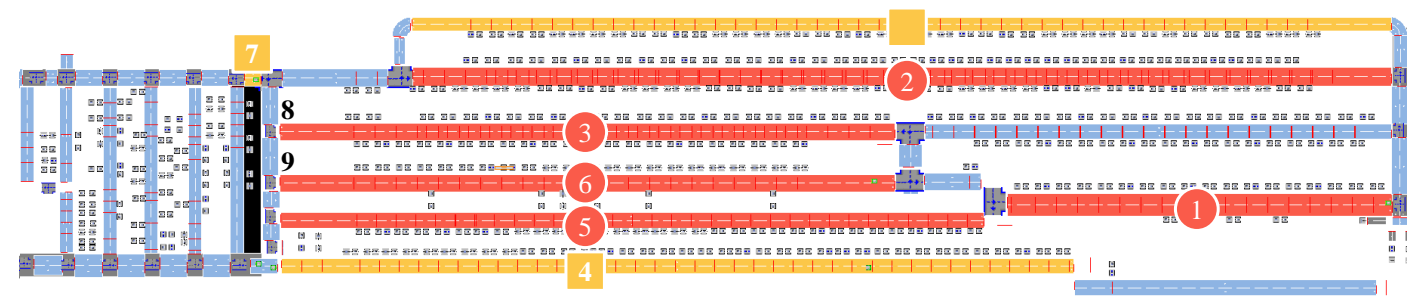

Figure 7. A heat map based on the workshop's layout and the number of interferences computed through the simulation of the scenario $\mathrm{C}$.

Also, the workshop's entrance and exit points are viewed as complicated ones. For example, in Figure 6, aisle number 7 receives the main entrance and exit doors to the assembling line. As a result, many logistics flows must pass by these locations.

To continue the interferences analyses, Table 7 indicates the main types of interferences. Moreover, for each scenario, we present the average value found through the simulations.

\begin{tabular}{lccc}
\hline & \multicolumn{3}{c}{ Scenarios } \\
Interferences & A & B & C \\
& Interferences & (units) \\
\hline Overtake & 402 & 465 & 475 \\
AGV Blocked & 67 & 0 & 64 \\
Waiting before the Intersection & 69 & 62 & 64 \\
Overtake with both vehicle moving & 47 & 50 & 5 \\
Overtaking not allowed & 1 & 1 & 1 \\
Total & 586 & 578 & 609
\end{tabular}

Table 7. Summary of the average number of interferences found during the experiments. Note that the values of each column refer to the average results computed through the simulation of the five-days data.

Table 7 suggests that the main disturbing item is the one related to overtaking. Indeed, the convoys must overtake themselves on many occasions, such as whenever slower AGVs are ahead, and a workmate is parked supplying materials. Also, the "blocked AGV" item has significant values in scenarios A and C because the current AGVs are able neither to overtake nor to make decisions. Consequently, it must interrupt its trajectory frequently. On the contrary, scenario B enables the AGV to overtake other vehicles. As a result, the interferences related to "blocked AGV" were 
significantly reduced, as well as the interferences' average duration.

Moreover, scenario B does not contribute to minimizing the total of interferences, as observed in figure 6 . However, the interferences, in that case, tend to be quicker. It is explained by the fact that the blocked AGV cases were replaced by the overtakes ones. The overtakes interferences are faster than blocked AGV interferences.

Regarding the impacts of scenario $\mathrm{C}$, on the one hand, that approach contributes to increasing the total number of interferences because the number of overtakes increases as well. On the other hand, it decreases the number of overtaking when both vehicles are moving, which is representative due to security reasons. Moreover, according to Table 6, the total of vehicles that pass through those aisles is reduced. In many situations, a vehicle goes back to the warehouse through the same aisle from where it was. That is counted as two vehicles by the system. It explains the high level of vehicles in scenarios A and B. Moreover, note in Figure 7 that aisles number 7 has reduced the number of interferences due to the application of scenario $\mathrm{C}$.

Concerning the routes' evaluation, Table 8 presents the results related to the introduced logistics flows. So, we report the following indicators for each route: (i) the total of backorders; (ii) the sum of the length the backorders last; (iii) routes' trip duration; and (iv) a route's trip distance. Once again, we assigned to each route its average value of each scenario.

Note that the considered routes are the supplying ones, which are the ones that supply materials with irregular consumption rates. 


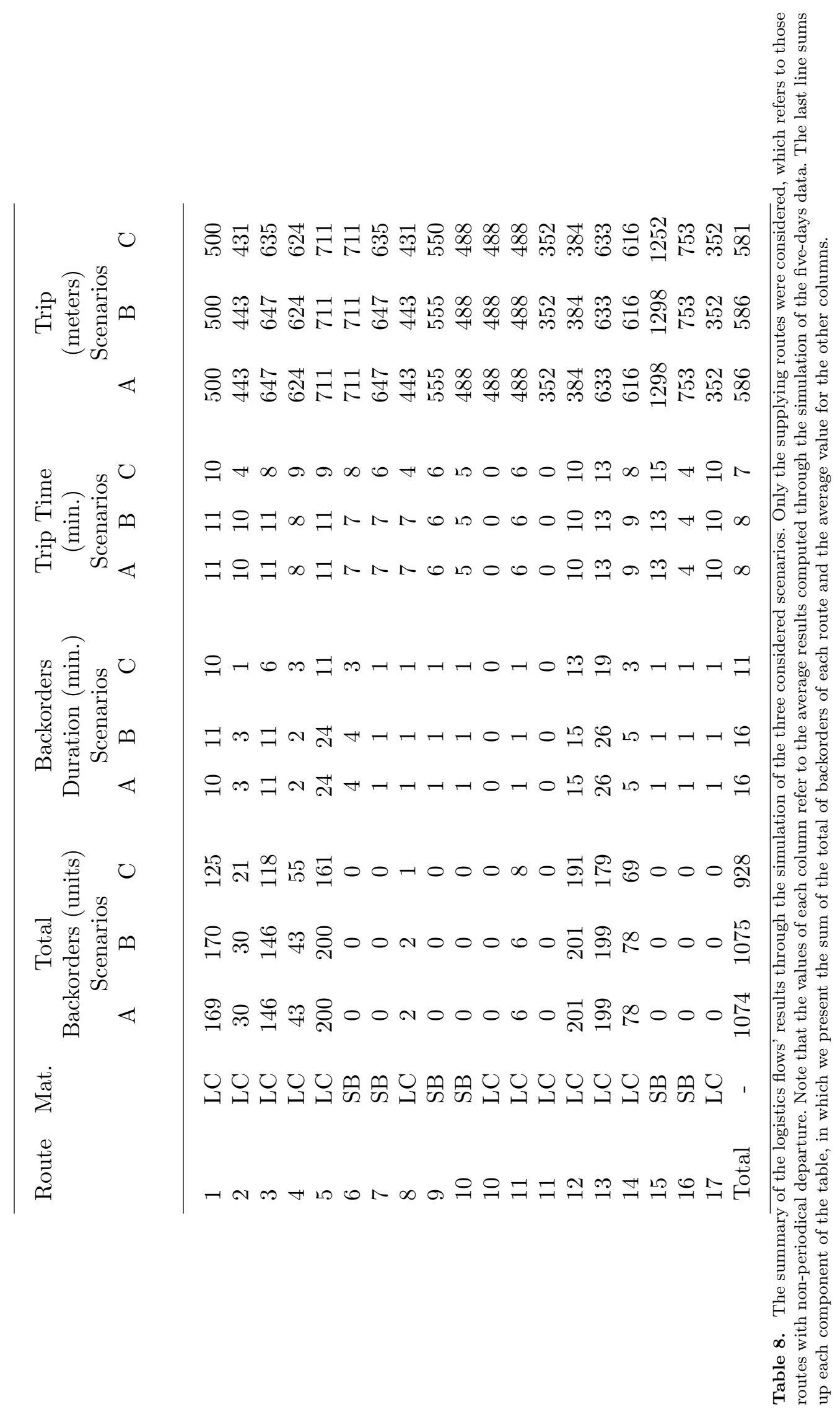


Concerning the results in Table 8, the first general analysis one may do is that the considered routes are not balanced. In other words, there are some logistics operators that received more load than others. As a result, the reassignment of the workstations into the routes should be considered. Besides, the SB routes are better to execute their tasks than the LC ones. Indeed, the LC routes presented the higher overall backorders values because the demand for LC is also higher.

Moreover, we can observe that scenarios A and B are quite similar because the autonomous AGVs does not impact the performance of other vehicles. Note that the AGV routes are not considered here because they do not supply materials with an unsteady consumption rate.

By contrast, scenario $\mathrm{C}$ do incur on a reduction of the level of backorders as well as a reduction on the backorders duration for most of the routes. It is explained because the routes were reorganized in such a way that the distance of their trips became a little shorter. Also, the routes were able to complete a trip faster than before, as presented in able 8 . Note that routes reconfiguration was necessary to adapt them to the new layout flows found in scenario $\mathrm{C}$.

Regarding the model's validation, we have presented the model structure and the computed results to the company's employees. They found them interesting and wondering about introducing it as a supportive methodology to evaluate logistics flows in other areas as well, for example, the WHS. We noticed that the graphical tools, such as the heat maps, are good options to promote a model validation. Consequently, this tool can be exploited to further application according to the needs of the decision-maker, such as building a heat map based on the number of backorders of each workstation.

To conclude, the authors suggest that scenario $\mathrm{C}$ should be tested in practice because of its overall performance in reducing the number of backorders. Also, it is a cheaper scenario than the autonomous AGV one. However, scenario $\mathrm{C}$ requires effort to organize all the routes' trajectories and processes because it impacts on many of them.

Also, the following managerial insights may be interpreted based on the previous results: (i) workshop areas that receive a high number of workstations are likely to be defined as a conflicting one; (ii) shorter routes may implicate in a fewer number of backorders as well as the average duration a backorder last. So, the longer a route is and the more workstations it receives, a higher level of backorders it will have; (iii) single-flow aisles may increase the traffic security because it minimizes both the number of overtakes with two moving vehicles and the chance of frontal accidents; (iv) the introduction of autonomous AGV supports the ILF to become more fluid because there are not issues regarding blocked AGV. However, the number of overtakes in the workshop will increase; (v) heat-maps are a suitable tool to present results to stakeholders because these maps are straightforward and widely accepted by them.

\section{Conclusions}

In this work, we face a real-world case study over internal logistics operations in a car assembling company. The company's workshop contains two assembly lines that are able to produce more than 1,000 cars each day.

We introduce an ILF simulation based on a DES model to evaluate the workshop' aisles and a set of logistics flows. The primary objective is to identify the main bottlenecks in the assembly line under the logistics perspective, such as the flows' obstructions or interferences. 
The study was carried out in a real car-assembling company, considering real data and actual assembly-line operations. Also, two further scenarios were evaluated. The first scenario introduced autonomous AGVs that can overtake other vehicles. The second one referred to an one-flow policy in the workshop's aisles. The results show which aisles are overused, the disturbance among the logistics flows, and the logistics flow's performance regarding the total of backorders, trips duration, and the routes' length in terms of distances and time.

As a result, this paper contributes to both the literature and industry. First, a DES model is provided, which aims is to assess the ILF in a car-assembling workshop. Second, we provide a set of best practices for bench-marketing purposes for those who want to develop DES models centered on ILF analysis. Then, focusing on real operations, we propose a set of managerial insights related to ILFs in assembling lines that can impact the efficiency of the logistics operations.

Figure 8 summarizes the main module that should compose a DES model to assess internal logistics flows. This framework is based on the work of (Harrison, Memarpour, Mardani, Shakibayifar, Bakhshayeshi, \& Espahbod, 2019). Note that the content applied in this work can be adapted easily to further applications such as warehouse operations. Usually, internal logistics flow studies share standard features regardless of their application, such as traffic flow control, routes behavior, and orders management.

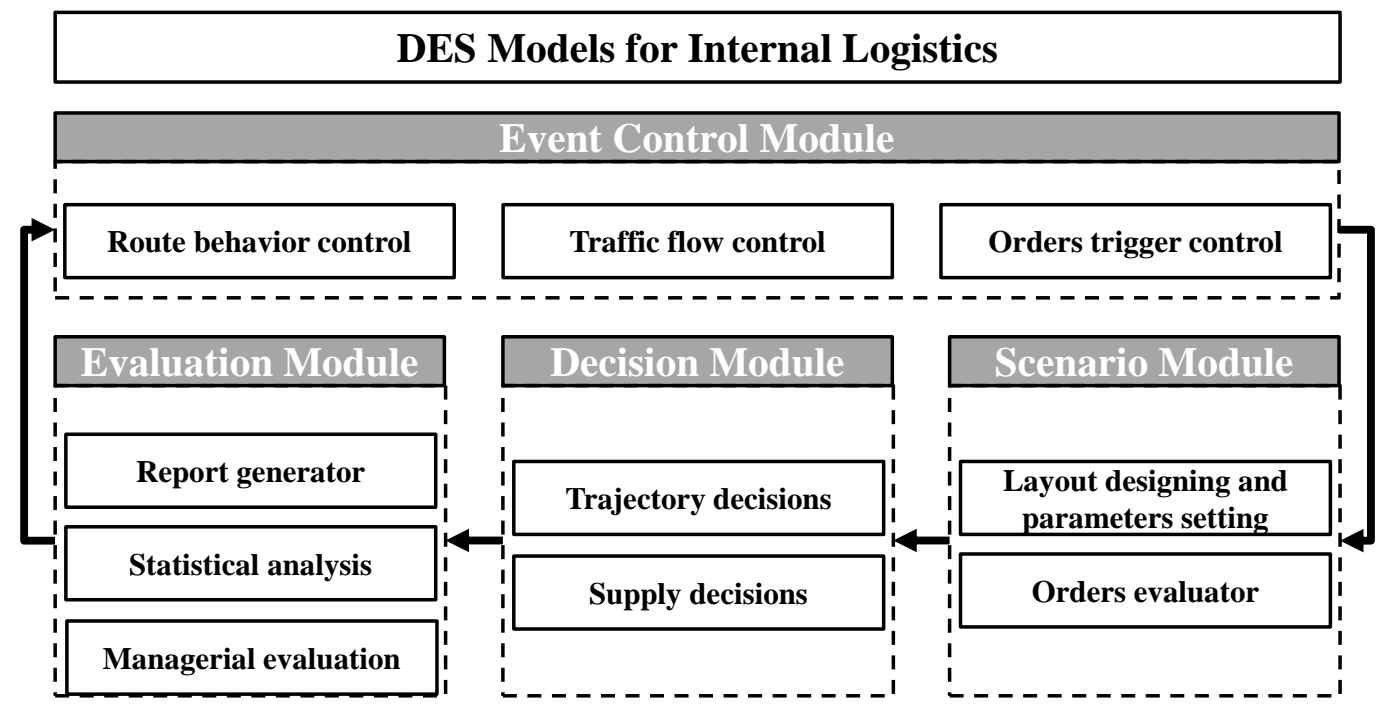

Figure 8. A DES model framework for Internal Logistics applications. This scheme summarizes the applications discusses in Section 4.

To conclude, the study was presented to the company's employees that found it interesting. Indeed, they propose to extend it to WHS's flows. The proposed extension may be viewed as future work. Concerning further applications, it would be interesting to introduce those concepts developed for external logistics into internal logistics, such as driver behavior. Also, methods should be approached to support the company to compute those routes, such as a metaheuristic algorithm that faces combinatorial optimization problems. Later, those routes may be introduced and tested in a similar DES model. 


\section{Acknowledgments}

This work has been partially supported by the Industrial Ph.D. of Government of Catalonia (2016DI022) (Marcelus Fabri) and by the Government of Catalonia through the projects (2017-SGR-1739) (Helena Ramalhinho, Miquel Oliver). The authors are also thankful to Ms. Simona Kusynova, Ms. Montserrat Oriol, and all the employees of SEAT S.A that contributed to this paper. Finally, the authors would like to thank the anonymous reviewers for their valuable comments that considerably improved the quality of this paper.

\section{References}

Atieh, A. M., Kaylani, H., Al-abdallat, Y., Qaderi, A., Ghoul, L., Jaradat, L., \& Hdairis, I. (2016). Performance improvement of inventory management system processes by an automated warehouse management system. Procedia Cirp, 41, 568-572.

Banks, J., Carson, I. I., Nelson, B. L., \& Nicol, D. M. (2005). Discrete-event system simulation. Pearson.

Brooks, R. J., \& Robinson, S. L. (2001). Simulation and Inventory Control (Texts in Operational Research). Palgrave Macmillan.

Braekers, K., Ramaekers, K., \& Van Nieuwenhuyse, I. (2016). The vehicle routing problem: State of the art classification and review. Computers $\mathcal{E}$ Industrial Engineering, 99, 300-313.

Caridade, R., Pereira, T., Ferreira, L. P., \& Silva, F. J. G. (2017). Analysis and optimisation of a logistic warehouse in the automotive industry. Procedia Manufacturing, 13, 1096-1103.

Cujan, Z. (2016). Simulation of production lines supply within internal logistics systems. Open Engineering, 6(1).

Fabri, M., Ramalhinho, H., de Souza, M. C., Ravetti, M. G. (2019). The Lagrangean Relaxation for the Flow Shop Scheduling Problem with Precedence Constraints, Release Dates and Delivery Times. Journal of Advanced Transportation, 2019.

Faget, P., Eriksson, U., \& Herrmann, F. (2005, December). Applying discrete event simulation and an automated bottleneck analysis as an aid to detect running production constraints. In Proceedings of the 37th conference on Winter simulation (pp. 1401-1407). IEEE.

Gagliardi, J. P., Renaud, J., \& Ruiz, A. (2007, December). A simulation model to improve warehouse operations. In Proceedings of the 39th conference on Winter simulation: 40 years! The best is yet to come (pp. 2012-2018). IEEE Press.

Hassannayebi, E., Memarpour, M., Mardani, S., Shakibayifar, M., Bakhshayeshi, I., Espahbod, S. (2019). A hybrid simulation model of passenger emergency evacuation under disruption scenarios: A case study of a large transfer railway station. Journal of Simulation, 9 1-25.

Harrison, G., \& Thiel, C. (2017). Policy insights and modelling challenges: The case of passenger car powertrain technology transition in the European Union. European Transport Research Review, 9(3), 37.

Higgins, M., Ladbrook, J., Khalwadekar, G., \& Osman, M. (2019). Deterministic simulation and graphical representation of powered material handling vehicle movements to enhance pedestrian safety at the Ford Motor company. Journal of Simulation, 1-11.

Hillier, F. S., \& Lieberman, G. J. (1995). Introduction to operations research. McGraw-Hill Science, Engineering \& Mathematics.

Horta, M., Coelho, F., \& Relvas, S. (2016). Layout design modelling for a real world just-intime warehouse. Computers \& industrial engineering, 101, 1-9.

Lima, M., Ramalhinho, H. (2017, December). Designing internal supply routes: A case study in the automotive industry. In 2017 Winter Simulation Conference (WSC) (pp. 3358-3369). IEEE.

Ludavicius, E., \& Ali, A. (2014). Modeling and simulation of automotive engine sub-assembly for production improvement. In Proceedings of the International Conference on Industrial 
Engineering and Operations Management (pp. 2040-2049).

Klug, F. (2013). The internal bullwhip effect in car manufacturing. International Journal of Production Research, 51(1), 303-322.

Macal C. M. \& North M.J. (2010). Tutorial on agent-based modelling and simulation. Journal of Simulation, 4(3), 151-162.

Martínez-Barberá, H., \& Herrero-Pérez, D. (2010). Autonomous navigation of an automated guided vehicle in industrial environments. Robotics and Computer-Integrated Manufacturing, 26(4), 296-311.

Mason, S. J., Ribera, P. M., Farris, J. A., \& Kirk, R. G. (2003). Integrating the warehousing and transportation functions of the supply chain. Transportation Research Part E: Logistics and Transportation Review, 39(2), 141-159.

Mehami, J., Nawi, M., \& Zhong, R. Y. (2018). Smart automated guided vehicles for manufacturing in the context of Industry 4.0. Procedia Manufacturing, 26, 1077-1086.

Michalos, G., Makris, S., Papakostas, N., Mourtzis, D., \& Chryssolouris, G. (2010). Automotive assembly technologies review: challenges and outlook for a flexible and adaptive approach. CIRP Journal of Manufacturing Science and Technology, 2(2), 81-91.

Muñuzuri, J., Larrañeta, J., Onieva, L., \& Cortés, P. (2005). Solutions applicable by local administrations for urban logistics improvement. Cities, 22(1), 15-28.

Negahban, A., \& Smith, J. S. (2014). Simulation for manufacturing system design and operation: Literature review and analysis. Journal of Manufacturing Systems, 33(2), 241-261.

Patchong, A., Lemoine, T., \& Kern, G. (2003). Improving car body production at PSA Peugeot Citroen. Interfaces, 33(1), 36-49.

Poon, T. C., Choy, K. L., Chow, H. K., Lau, H. C., Chan, F. T., \& Ho, K. C. (2009). A RFID case-based logistics resource management system for managing order-picking operations in warehouses. Expert Systems with Applications, 36(4), 8277-8301.

Ribino, P., Cossentino, M., Lodato, C., \& Lopes, S. (2018). Agent-based simulation study for improving logistic warehouse performance. Journal of Simulation, 12(1), 23-41.

Roman-Verdugo, O. (2014). Diagnóstico de Flujo del Área de Carrocerías de la Planta Ford de estampado y ensamble de Hermosillo, Sonora, México. Produção em Foco, 4(2).

Ruiz-Torres, A. J., \& Nakatani, K. (1998, December). Application of real-time simulation to assign due dates on logistic-manufacturing networks. In 1998 Winter Simulation Conference. Proceedings(Cat. No. 98CH36274) (Vol. 2, pp. 1205-1210). IEEE.

Sachan, A., \& Datta, S. (2005). Review of supply chain management and logistics research. International Journal of Physical Distribution Logistics Management, 35(9), 664-705.

Semini, M., Fauske, H., \& Strandhagen, J. O. (2006, December). Applications of discrete event simulation to support manufacturing logistics decision-making: a survey. In Proceedings of the 38th conference on Winter simulation (pp. 1946-1953). Winter Simulation Conference.

Seebacher, G., Winkler, H., \& Oberegger, B. (2015). In-plant logistics efficiency valuation using discrete event simulation. International Journal of Simulation Modelling, 14(1), 60-70.

Tako, A. A., \& Robinson, S. (2012). The application of discrete event simulation and system dynamics in the logistics and supply chain context. Decision support systems, 52(4), 802815.

Valentin, E. C., Verbraeck, A., \& Sol, H. G. (2003). Advantages and disadvantages of building blocks in simulation studies: A laboratory experiment with simulation experts. In Proceedings ESS (pp. 141-148).

Vavrík, V., Gregor, M., \& Grznár, P. (2017). Computer simulation as a tool for the optimization of logistics using automated guided vehicles. Procedia engineering, 192, 923-928.

Vis, I. F. (2006). Survey of research in the design and control of automated guided vehicle systems. European Journal of Operational Research, 170(3), 677-709.

Wang, H. F., \& Chang, C. M. (2015). Facility layout for an automated guided vehicle system. Procedia Computer Science, 55, 52-61.

Wilding, R., Wagner, B., Gligor, D. M., \& Holcomb, M. C. (2012). Understanding the role of logistics capabilities in achieving supply chain agility: a systematic literature review. Supply Chain Management: An International Journal. 
Zhou, B., \& Peng, T. (2017). Scheduling the in-house logistics distribution for automotive assembly lines with just-in-time principles. Assembly Automation, 37(1), 51-63. 